\title{
Editorial
}

\section{El Salvador cinco años después}

Hace ya casi cinco años, al asumir su cargo, el presidente Calderón aseguró que tenía "un sólo gran compromiso: con El Salvador, con su pueblo, para construir un futuro mejor" (ver ECA, 547-548, 1994, p. 601ss.). Aun cuando era consciente de las dificultades de esta empresa, tanto que no deseaba "levantar falsas expectativas, porque en el camino del progreso no hay milagro", conviene revisar, cinco años después, en qué estado deja a $\mathrm{El}$ Salvador su gobierno, es decir, si ha cumplido la misión que él mismo se impuso de "trabajar con la suficiente eficacia para que el pueblo compruebe, en su vida cotidiana, los beneficios de la democracia no sólo en el plano político, sino en las áreas económicas, sociales y culturales". En realidad, al contrastar promesas y realidad, le tomamos en serio la palabra al presidente Calderón.

No hay por qué dudar de su buena intención cuando, al iniciar su mandato, se propuso sentar los fundamentos para crear un "nuevo" El Salvador. La novedad, según el discurso programático del 1 de junio de 1994, vendría dada por "la legalidad, la seguridad, la honestidad, el respeto humano, la solidaridad y la apertura". Es así como el presidente Calderón esperaba "convertir El Salvador en un país de oportunidades con movilidad social" y garantizar la paz social. El análisis objerivo, sin embargo, debe ir más allá de las intenciones y los propósitos, y debe tomar en cuenta que no sólo somete a examen la gestión presidencial, sino también el desempeño del Partido ARENA y, de alguna manera, el de los otros dos órganos del Estado. Tampoco debe perder de vista la incidencia de variables regionales e internacionales, que el presidente salvadoreño no controla.

\section{Una economía débil y vulnerable}

Uno de los logros más destacados del gobierno de Calderón es haber conservado la estabilidad macroeconómica, pero al mismo tiempo ésta constituye una de sus limitaciones más grandes, porque no ha estimulado la 
productividad de la economía nacional ni ha hecho avanzar el área social en la dirección prevista. La solidaridad y la paz social eran elementos importantes del nuevo país que Calderón ofreció. En la misma línea de su antecesor, quien prometió gobernar para los más pobres de los pobres, el presidente Calderón también se propuso trabajar "sin descanso para elevar la calidad de vida, sobre todo de los más necesitados, para que ningún salvadoreño quede fuera de la gran corriente del desarrollo". De esta manera, según su propia formulación, esperaba "romper con la fatalidad de que el que nace pobre esté condenado a morir pobre".

A la mayoría de la población no le ha pasado desapercibido el logro macroeconómico. Al finalizar el año 1998, según una encuesta del Instituto Universitario de Opinión Pública (IUDOP), ha desplazado del primero al segundo lugar de sus preocupaciones principales los aspectos relacionados con la economía. La inflación (4.2 por ciento en 1998, próxima al nivel internacional) ya no figura como un problema, pero sí la pobreza y el desempleo.

El gobierno de Calderón se enfrentó a un dilema, heredado de su antecesor, que él tampoco pudo resolver: satisfacer las necesidades básicas de la mayoría de la población, por un lado, y conservar la estabilidad macroeconómica y mantener bajo control la inflación, por el otro. Al final, su gobierno se inclinó por el segundo extremo del dilema, descuidando el primero, y promovió una política demasiado restrictiva, cuyas consecuencias en el empleo, el acceso a los servicios sociales elementales, de los cuales los pobres dependen en gran medida, y en el nivel de pobreza general son negativas.

Las "Encuestas de hogares y propósitos múltiples" de 1997 muestran que el 49 por ciento de todos los hogares salvadoreńos vive en pobreza -el 20 por ciento en pobreza extrema y el 29 por ciento en pobreza relativa-y que la pobreza se concentra en el sector rural, donde se encuentra el 62 por ciento de todos los hogares pobres del país, en contraposición al 48 por ciento que se haya en la ciudad. Este desequilibrio se expresa en ingresos bajos, menor nivel de vida, vida más corta y menos acceso a los servicios educativos, de salud y saneamiento. La mayor parte del ingreso de estos hogares pobres es empleada en la adquisición de alimentos.

El gobierno de Calderón no pudo encontrar el camino para reducir de forma significativa este nivel de pobreza, entre otras cosas, porque no superó dos limitaciones estructurales: el bajo nivel tanto del crecimiento económico como de la recaudación tributaria. Sin una tasa elevada y sostenida de crecimiento económico es imposible reducir la pobreza. Los expertos calculan que El Salvador necesita una tasa de crecimiento anual alrededor del 6 por ciento, nivel no alcanzado desde 1995. Cabe advertir, sin embargo, que esta tasa elevada, en sí misma, no es suficiente para reducir la pobreza. En los primeros años de la década, cuando la tasa de crecimiento tendió hacia 
arriba hasta alcanzar el pico de 1995, la pobreza siguió prevaleciendo en El Salvador. El crecimiento no significa, pues, retroceso de la pobreza. Más aún, se ha podido constatar que algunos sectores pobres no son sensibles al crecimiento. Los pobres rurales y sobre todo los hogares rurales sostenidos por mujeres están al margen de los beneficios del crecimiento. El crecimiento económico contribuye a la disminución de la pobreza de forma determinante cuando potencia la productividad del trabajo, genera nuevas fuentes de empleo -en particular en las áreas rurales, donde se concentra la pobreza-, eleva los salarios y se asignan

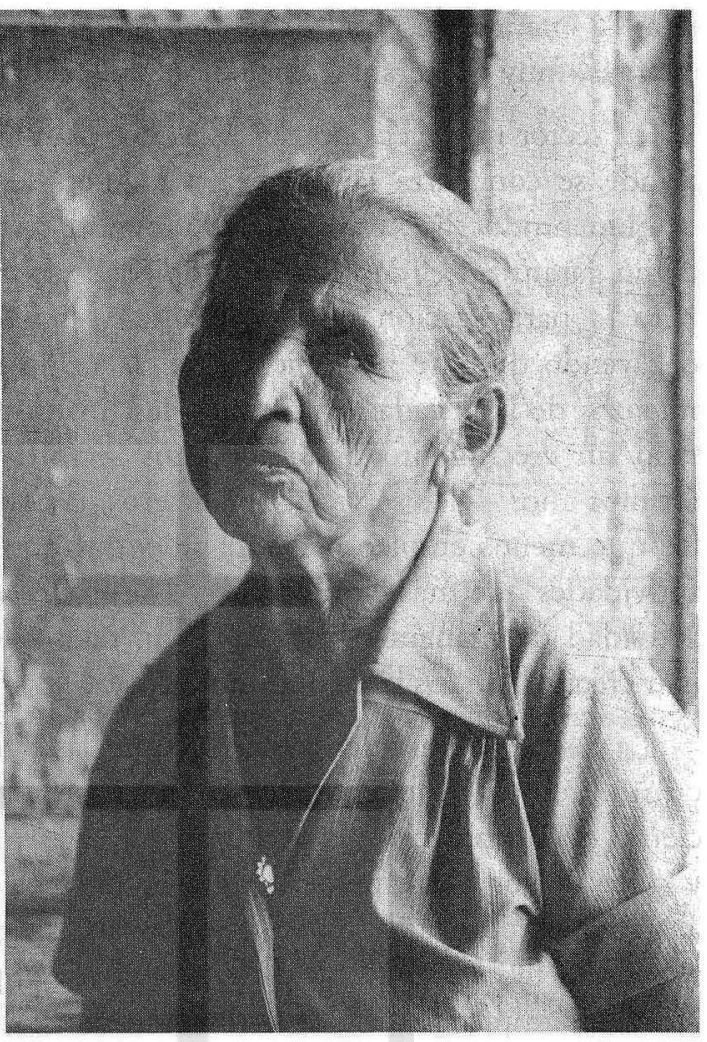
recursos a salud, educación y vivienda. Pero para ello son necesarias políticas sectoriales y programas específicos.

El crecimiento del Producto Interno Bruto en 1998 fue estimado entre un 4 y 5 por ciento, por debajo del nivel requerido para cumplir las metas propuestas - "nuestro desafío es mantener altas tasas de crecimiento y transformarlas en desarrollo económico con equidad". Sin embargo, las pérdidas ocasionadas por la tormenta Mirch en el sector agropecuario -en particular en la producción de granos básicos, pero también en el café, la caña de azúcar y la pesca - han disminuido el crecimiento esperado al 363.5 por ciento (ver Departamento de Economía, "Análisis de conyuntura", No. 2, en esta misma edición). Es muy probable que en 1999 se experimente una reducción similar, porque la destrucción de la tormenta no sólo afectó el ciclo agrícola de 1998, sino que también el del ańo siguiente, a causa de la degradación del suelo. El café, uno de los productos de exportación más importantes, no sólo ha sido afectado por la tormenta, sino también por el fenómeno del Niño y la caída del precio internacional. Aunque la tendencia de las otras exportaciones es hacia arriba, la cantidad total está muy por debajo de las expectativas para 1998. Como consecuencia de lo anterior, la maquila ha desplazado al café al segundo lugar. Todo esto muestra la incapacidad de la economía salvadoreña para responder a los retos que su pobla- 
ción le plantea. Es una economía con limitaciones estructurales graves y, además, muy vulnerable a los fenómenos naturales.

El sector más afectado por estas dos debilidades es el rural, precisamente, donde se concentra la pobreza. Calderón se comprometió a "fomentar el cambio productivo, estimular el progreso tecnológico y la capacitación, así como garantizar el derecho de propiedad y seguridad personal en el campo", pero la participación de la agricultura en la economía nacional continuó decayendo durante su gobierno, tal como lo ha venido haciendo desde comienzos de la década. En cambio, las finanzas y los seguros han experimentado un crecimiento destacado. Los sectores que más han crecido en los últimos años - los servicios financieros, la construcción y la industria- son los que menos empleo gerieran; mientras que la agricultura, una de las dos actividades que más empleo crea - la otra es el comercio-, ha reducido su actividad de manera significativa. En consecuencia, los sectores que menos han crecido son los que muestran las tasas más elevadas de desocupación.

La tasa de desempleo abierto, según las cifras oficiales, asciende al 7 por ciento. Pero el problema mayor está en el sector informal, donde el 50 por ciento de la población económicamente activa está empleada o subempleada y cuya mayor parte percibe ingresos muy bajos. Sin embargo, el gobierno alega haber alcanzado su meta - "buscamos ampliar las fronteras productivas y nuestras fuentes generadoras de recursos y empleos permanentes"-, pues en 1998, el empleo habría crecido, tal como estaría comprobado en el crecimiento de cotizantes al seguro social. El fundamento del argumento es débil, porque el sector informal no cotiza, porque podría indicar que ahora cotizan quienes antes no lo hacían y porque no hay información sobre el subempleo.

Estos desequilibrios en el crecimiento de los diferentes sectores se explican por la rentabilidad. El crecimiento rápido de la actividad financiera se debe a su elevada rentabilidad, así como el abandono de la agricultura es indicio de su contrario. La orientación del crédito es una consecuencia de lo anterior. Por lo tanto, cualquier gobierno futuro, interesado en reactivar la agricultura, deberá buscar la manera para estimular el crecimiento armónico de todos los sectores de la actividad económica. Pero, entonces, el criterio no debiera ser sólo la rentabilidad, sino sobre todo el bienestar de la población.

La evolución del salario mínimo es similar a la de la economía. Desde 1995, cuando la actividad económica dio las primeras señales de desaceleración, el poder adquisitivo de los trabajadores también comenzó a experimentar una contracción, la cual se ha conservado hasta ahora. Los ligeros incrementos en el salario mínimo, que representa el único ingreso de la inmensa mayoría de los trabajadores con empleo formal, es insuficiente para adquirir la canasta básica de consumo - aun cuando un mismo hogar perciba dos salarios mínimos. El sector privado se opone a elevar el salario mínimo, alegando que ocasiona desempleo. Sin embargo, el aumento del 8 por 
ciento efectuado en 1998 no parece haber afectado el nivel de empleo y, en cambio, ha favorecido a los trabajadores, aunque no ha sido lo suficientemente elevado como para que éstos puedan recuperar su poder adquisitivo (ibid.).

El gobiemo de Calderón no pudo encontrar el camino para reducir de forma significativa este nivel de pobreza, entre otras cosas, porque no superó dos limitaciones estructurales: el bajo nivel tanto del crecimiento económico como de la recaudación tributaria.

La mujer sería una prioridad del gobierno actual — "para ellas crearemos programas que les permitan mejorar su nivel de vida. Además [las] protegeremos en forma especial". Pero éstas, además de las responsabilidades domésticas, deben salir a trabajar y cuando encuentran empleo, perciben un salario inferior al de los hombres por una tarea similar. Esto significa que, aparte de no ser valoradas socialmente, su trabajo remunerado no equivale a un ingreso más elevado, lo cual les permitiría elevar su nivel de vida.

La inflación baja favorece a toda la sociedad, aunque no lo hace de la misma manera para todos sus miembros. El deterioro histórico del salario de los trabajadores limita los beneficios de una inflación baja. Los precios de los alimentos de la canasta básica subieron en 1998 a consecuencia de las pérdidas que el Mitch causó en la cosecha de granos básicos. En cambio, los precios del vestido y el calzado tendieron a disminuir - debido a la apertura del comercio exterior y a la reducción de aranceles-, pero la mayor parte de los ingresos de los hogares pobres son empleados en adquirir alimentos. Con todo, la inflación salvadoreña es de las más bajas del continente y lo seguirá siendo si se mantiene la política restrictiva y el tipo de cambio fijo y si no ocurre ningún desastre natural.

El gobierno de Calderón ha hecho poco por un sector tan importante como la micro y la pequeña empresa y por el sector informal, donde se concentra una gran parte de la población económicamente activa y que, además, tiene un gran potencial para crear alternativas económicas. En su primer discurso, al dirigirse a este sector, el presidente le prometió que los "programas de capacitación [...] tendrán una importancia especial [...] orientados a elevar la capacidad productiva y la eficiencia". Aparte de crear, casi al final de su mandato, una instancia (CONAMYPE) para asumir estas tareas, la mayor parte de la capacitación y la asistencia técnica y financiera gubernamental ha estado orientada a la mediana empresa. De los otros sectores más pequeños se ha hecho cargo la cooperación internacional estadounidense, belga, alemana y suiza. 
La segunda debilidad importante del gobierno actual es la fiscal. A pesar del nivel del crecimiento económico, la carga tributaria (como proporción del Producto Interno Bruto) ha venido disminuyendo desde 1995. En los últimos tres años, ha representado alrededor del 11 por ciento, cuando, en realidad, la capacidad del país se aproxima al doble de ese porcentaje. De hecho, es una de las cargas más bajas de América Latina. La evasión -a la cual el presidente Calderón prometió "combatir con decisión"-, estimada entre el 7.2 y el 9.2 por ciento del Producto Interno Bruto, es muy elevada respecto a lo recaudado. Más de la mitad del impuesto al valor agregado se esfuma por evasión y elusión (exenciones fiscales, la mayoría de las veces no justificadas, que reflejan la presión de grupos de poder). No es créible que sólo 4,118 personas declaren una renta imponible superior a los $200 \mathrm{mil}$ colones anuales. Tampoco es posible que los contribuyentes del Impuesto al Valor Agregado hayan disminuido el 1 por ciento, mientras que las empresas que pagan impuesto sobre la renta hayan experimentado una reducción del 16.4 por ciento. Esto significa que la evasión del impuesto sobre la renta ha aumentado o que muchas empresas no son rentables y, por lo tanto, debieran haber cerrado sus puertas (ibid.). A todo esto hay que agregar el contrabando - una práctica muy arraigada y voluminosa-, la corrupción y la ineficiencia y la arbitrariedad de la administración tributaria (Comisión Nacional de Desarrollo, Temas claves para el plan de nación. Consulta especializada).

No parece, pues, que el gobierno de Calderón se haya esmerado por "buscar el incremento real de los ingresos de los trabajadores", creando empleo, tal como lo prometió. El crecimiento económico promovido por su gobierno no está centrado en la persona; de ser así, hubiera creado empleo y elevado el salario real. En vez de ello, el gobierno ha privilegiado la política de estabilización, absolutizando una tasa de inflación baja, a costa de menos productividad, lo cual se traduce en menos producción por. reducción de la demanda y en condiciones de vida peores por disminución del empleo y la capacidad adquisitiva de los trabajadores.

La tasa de desempleo abierto, según las cifras oficiales, asciende al 7 por ciento. Pero el problema mayor

está en el sector informal, donde el 50 por ciento de la población económicamente activa está empleada o subempleada y cuya mayor parte percibe ingresos muy bajos.

\section{La realidad social: un límite insuperable}

Estos datos no sólo reflejan la debilidad del Estado salvadoreño, sino que además se convierten en una barrera infranqueable para atender las necesida- 
des crecientes de la población más pobre del país. En estas condiciones es imposible asignar al gasto social el 50 por ciento del presupuesto nacional, tal como el presidente Calderón prometió al comienzo de su gobierno. No obstante los incrementos hechos a lo largo de los últimos cinco años, la asignación para gasto social en el presupuesto de 1999 asciende al 35.6 por ciento.

Educación ha sido uno de los rubros más favorecidos, lo cual ha permitido impulsar la reforma del sistema. Gracias a ella se han podido identificar algunos de los problemas más graves, se han trazado planes para superarlos y se han dado los primeros pasos en esa dirección. Sin embargo, todavía queda mucho por hacer. El Salvador sigue siendo uno de los países latinoamericanos con los indicadores educativos más bajos. Aunque el gobierno de Calderón ha hecho un gran esfuerzo presupuestario en este campo, el gasto en educación está todavía por debajo del de los países con un ingreso similar al salvadoreño. El Salvador cuenta con un nivel de analfabetismo muy elevado aún (15 por ciento) — cuando el presidente se comprometió a "reducir al mínimo el analfabetismo y llegar a una educación de calidad". El nivel de escolaridad sigue siendo bajo. La estructura del sistema educativo conserva la forma de una pirámide que se estrecha con demasiada rapidez. Comienza con una cobertura que se aproxima al 90 por ciento en educación básica, pero culmina con el 17 por ciento, en educación superior (ibid.). Tanto la oportunidad para entrar y permanecer en el sistema educativo como la calidad de la educación con frecuencia están estrechamente relacionadas al círculo vicioso de la pobreza, lo cual quiere decir que las carencias mayores están concentradas en el sector rural.

En cambio, la salud, donde se encuentran las privaciones más agudas de la población salvadoreña, tendrá que seguir esperando la "profunda reforma" prometida por Calderón. Aunque el presidente dijo que iba a "trabajar [...] dando énfasis a la salud primaria preventiva, buscando formas para descentralizar los servicios y lograr una mayor participación privada y de las comunidades", tres quintas partes de la población no tiene acceso adecuado a este servicio. Se observan deficiencias serias en la cobertura,

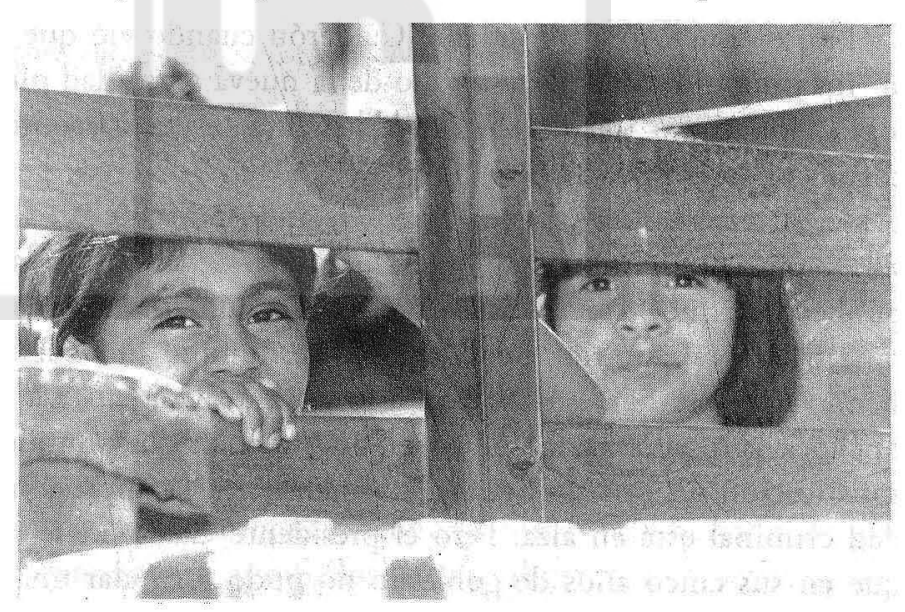


la calidad, la gestión y la administración del sistema. Este no tiene capacidad para atender las necesidades en el lugar donde se encuentran, sino que favorece la concentración de los servicios en centros grandes. Al igual que otros servicios, el sector más desatendido es el rural. Pese a una cobertura inmunológica aceptable y a la ampliación de la red sanitaria, aún predominan las patologías de la pobreza, similares a las de hace 50 años, aunque con menor frecuencia y letalidad. El Salvador muestra los índices más bajos del área centroamericana en el campo de la salud (ibid.). Más de 40 organizaciones no gubernamentales especializadas se esfuerzan por prestar un servicio que, por su naturaleza, corresponde al Estado.

Poco ha hecho el gobierno de Calderón para disminuir el déficit habitacional, el cual afecta a unos dos millones de personas. Más de la mitad de la población vive en condiciones inferiores a las aceptables y la construcción de viviendas es una de las actividades que más ha contribuido a la degradación de los recursos naturales renovables. El 51.9 por ciento del déficit se encuentra en el campo (ibid.). Al iniciar su período, el presidente Calderón prometió "ser más audaces y encontrar nuevas formas" para enfrentar este déficit, pero, de hecho, la inversión pública no ha sido orientada a satisfacer las necesidades de los sectores más afectados por la falta de vivienda, sino que ha privilegiado la construcción de infraestructura, algo necesario para estimular el crecimiento. De hecho, es una de las obras gubernamentales que inás aprecia la población.

En una situación similar se encuentra la problemática del medio ambiente - -sobre la cual el presidente Calderón prometió "políticas que logren una complementariedad entre el crecimiento y el medio ambiente"-, cuya legislación y ministerio caracen de fuerza para comenzar a revertir el deterioro alarmante.

\section{Una tarea pendiente: la institucionalización del Estado}

No se equivocó el presidente Calderón cuando vio que era menester dar la "máxima prioridad al desarrollo de la nueva seguridad pública" y, como es lógico, prometió trabajar "incansablemente" en este asunto, pero se quedó corto. No se equivocó porque, al final de su gobierno, la inseguridad es el principal problema de la población, seguido muy de cerca por el desempleo y la pobreza. La impresión general, incluso de las autoridades de seguridad pública, es que la actividad criminal ha aumentado. Pero las estadísticas muestran lo contrario, que tiende a disminuir, aun cuando aquélla sigue siendo muy elevada, en relación a lo normal. Una curiosa combinación publicitaria, protagonizada por los grandes medios de comunicación social, y la sofisticación del crimen organizado mantienen la impresión de que la actividad criminal está en alza. Pero el presidente Calderón se quedó corto, porque en sus cinco años de gobierno no pudo formular una política criminal 
ni un plan de seguridad. Es paradójico que siendo uno de los problemas que más preocupa a la población y uno a los que el gobierno ha prestado mayor atención, éste no cuente aún con un registro oficial de su incidencia.

No obstante haber prometido "hacer de la Policía Nacional Civil una institución que dé una verdadera y amplia protección a la población [...] que nos haga sentirnos orgullosos de ella", al final del gobierno de Calderón, aquélla adolece de una dirección inadecuada, de descoordinación con el Ministerio de Seguridad y la Academia Nacional de Seguridad Pública y de un estric-

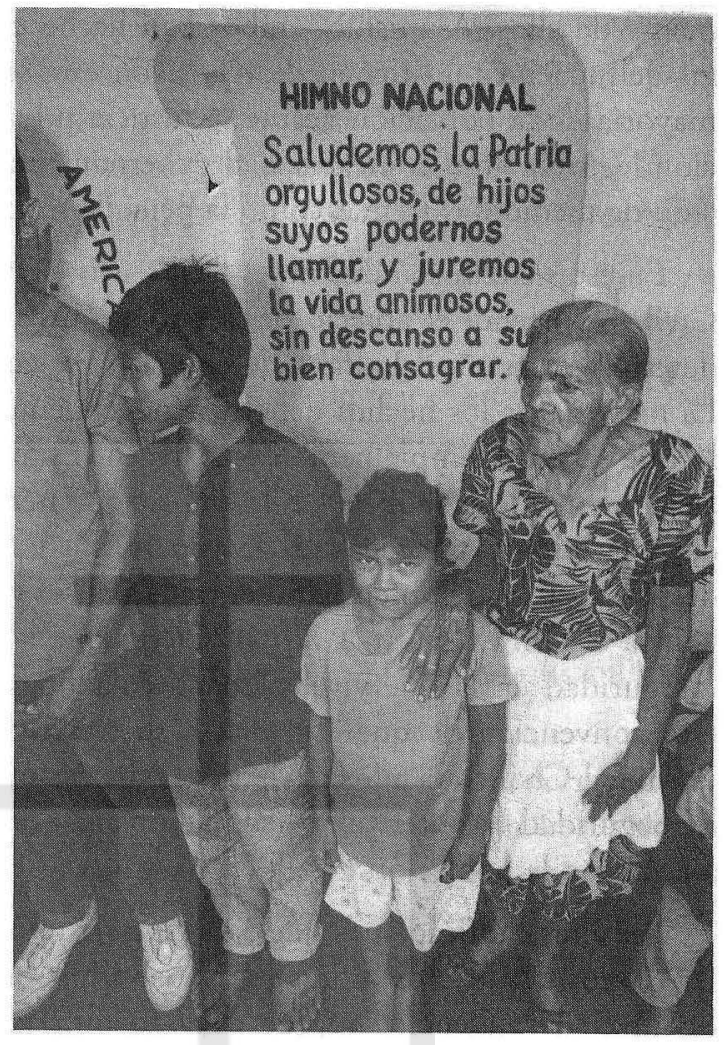
to control interno, que identifique y sancione a los agentes que violan las leyes. Una de las debilidades más graves de la policía es la ausencia de investigación criminal por incapacidad o por connivencia con el crimen organizado y las esferas del poder económico y político. Sin embargo, esta responsabilidad es compartida con el gobierno, porque éste ha frenado, por razones no reconocidas, pero que se adivinan con facilidad, la investigación del secuestro y la extorsión, del tráfico de drogas y armas, del lavado de dinero y de algunos asesinatos, vinculados a estas actividades o al poder mismo.

El Ministerio de Seguridad ha intentado con cierto éxito ocultar sus deficiencias, atribuyendo de manera machacona y a veces vociferante al Organo Judicial, en particular a los jueces y las leyes, el fracaso de la lucha contra el crimen. Al mismo tiempo, ha hecho varios intentos para comprometer a la población en tareas de seguridad -creando juntas de vecinos o grupos dedicados a vigilar y controlar las zonas residenciales. Si bien estas iniciativas, secundadas por la Asociación Nacional de la Empresa Privada, no tuvieron eco, en parte, porque podrían convertise en caldo de cultivo para la conformación de nuevos grupos armados, esta vez dedicados a la limpieza social, el gobierno y el sector privado consiguieron una primera modificación de los códigos penales, recientemente aprobados, e introdujeron una segunda de mayor trascendencia, como si la ineficacia de la policía dependiera principal- 
mente de ellos. Asimismo, ambos han hecho creer a la opinión pública que los delincuentes no tienen derechos. En este sentido, es preocupante que la mayoría de la población acepte la justicia privada y la venganza como reacción legítima ante la incapacidad gubernamental, así como también la adopción de medidas extremas como la pena de muerte.

En estas circunstancias no es fácil sentirse orgulloso de la Policía Nacional Civil. De hecho, el aprecio de la población ha ido disminuyendo a lo largo de estos cinco años. La falta de confianza se constata en la no colaboración. La mayoría de los hechos delictivos no es denunciada y los testigos no dicen lo que saben o simplemente desaparecen. Esta actitud se corresponde con el alejamiento de la policía de la población, frente a la cual aquélla con frecuencia adopta una actitud de superioridad, cuando no de prepotencia y desprecio. Esta desvinculación entre la policía y la sociedad hace que la lucha contra el crimen sea más difícil. Cierto que la población está cansada de la inseguridad en la que vive, pero no colaborará con la policía hasta que no esté convencida de que ésta está a su servicio. La manera como la Policía Nacional Civil trata a los testigos y la discrecionalidad con la que el Ministro de Seguridad ha intervenido en algunos casos relevantes no han contribuido a acercar a la población.

Las altas calificaciones que las empresas internacionales dedicadas a calcular riesgos financieros otorgan a El Salvador son contrarrestadas por el elevado nivel de violencia, una de cuyas manifestaciones más impactantes es la delincuencia. Las instituciones públicas responsables de la seguridad ciudadana no han podido consolidarse durante estos cinco años, no tanto por falta de recursos, como por adolecer de una dirección inadecuada y por falta de visión. El Ministerio de Seguridad y la Policía Nacional Civil proyectan una imagen de mucha actividad pero, en la práctica, obtienen muy pocos resultados. Su ineficiencia significa un elevado nivel de violencia y ésta, a su vez, mantiene alejada la inversión extranjera del país. De hecho, El Salvador es la nación centroamericana que menos se ha beneficiado con esta clase de inversión. La debilidad institucional al mismo tiempo que favorece la cultura de la violencia, socava las posibilidades económicas de El Salvador.

En la mejor tradición liberal, el gobierno de Calderón se dispuso a ser respetuoso de la ley y, en consecuencia, prometió (a) una gestión "enmarcada por la Constitución y las leyes"; (b) garantizar "la igualdad de todos los salvadoreños ante la ley"; (c) fortalecer el orden jurídico para que "el poder esté sujeto al derecho" y (d) "realizar lo que nos corresponda [...] para que el sistema de justicia esté acorde con los requerimientos de una sociedad moderna y democrática". A pesar de la importancia que el gobierno otorgó a la seguridad jurídica, su desempeño no ha sido destacado; tampoco ha sido peor que su antecesor. 
No obstante haber prometido "hacer de la Policía Nacional Civil una institución que dé una verdadera y amplia protección

a la población [...] que nos haga sentirnos orgullosos de ella", al final del gobierno de Calderón, aquélla adolece de una dirección inadecuada, de descoordinación con el Ministerio de Seguridad y ...

La igualdad ante la ley es todavía más formal que real y, en ese sentido, el poder, sobre todo el económico, en concreto la banca, no está aún sometida a la ley, tal como lo constatan tres fraudes y cuatro quiebras financieras - Crediclub, Finsepro, Insepro y Credisa. Los funcionarios públicos no se han distinguido por apegarse a la ley, sino que la administración de la cosa pública se ha llevado a cabo con bastante discrecionalidad. La evaluación a partir de resultados, la rendición de cuentas y la deducción de responsabilidades son prácticamente desconocidas.

Es claro que el gobierno actual no ha hecho todo lo que le correspondía para impulsar la modernización del Organo Judicial, pero también es verdad que éste tampoco se ha esforzado por reformarse. Es cierto que ahora cuenta con un presupuesto mayor, pero eso no se ha traducido en una administración de justicia pronta y debida. Los enfrentamientos entre el poder ejecutivo y el judicial, suscitados por diferencias entre el Ministro de Seguridad y la Corte Suprema de Justicia, además de haber causado escándalo, han contribuido a debilitar aún más la institucionalidad estatal. Ni la investigación policial ni la administración de justicia han mejorado sustancialmente. En descargo del gobierno saliente es menester reconocer la existencia de obstáculos para que prevalezca el derecho y que aquél ha hecho lo posible para orientar al país en esta dirección, pero sin conseguirlo del todo. Al menos no en grado tal como para poder afirmar que en El Salvador nadie está por encima de la ley.

El presidente Calderón hizo mucho énfasis en combatir la corrupción - "nuestra gestión no tolerará corrupción de ninguna índole" - y en gobernar de manera honesta - "nos comprometemos a una gestión pulcra y respetuosa de los asuntos públicos". Cinco años después, el gobierno salvadoreño no es menos corrupto que muchos otros gobiernos latinoamericanos. En todos los casos de corrupción ventilados en la prensa han aparecido implicados dirigentes de ARENA — los fraudes de Crediclub, Finsepro, Insepro y Credisa y en la apropiación indebida del Impuesto al Valor Agregado- y altos funcionarios del gobierno - FIS, FONAVTPO, administración fiscal, tráfico ilegal de vehículos y seguro social. El hasta hace poco viceministro de vivienda aparece en las juntas directivas de Credisa, FONAVIPO y de una empresa constructora que deforesta la cordillera del Bálsamo. El presidente Calderón 
no sólo no ha combatido la corrupción, sino que ha sido tolerante con los corruptos. De esta manera, su gobierno no ha sido "pulcro" ni ha respetado la cosa pública.

Los gobiernos de ARENA han considerado la privatización como el equivalente a la modernización del Estado - "buscaremos formas adecuadas para descentralizar y estimular la participación privada en los servicios del gobierno, en forma ordenada y gradual" dijo el presidente Calderón-, pero, en realidad, ha sido una oportunidad para la corrupción, Ante la experiencia de Cristiani, quien dejó la presidencia acusado de corrupción, el presidente Calderón prometió transparencia, pero no ha podido despejar la sospecha que aún pesa sobre el gobierno. Por orro lado, la privatización ha sido considerada como un fin y no como lo que es, un medio. Es así como el gobierno creyó que al privatizar, el Estado se modernizaría de manera inmediata. Según esta lógica mecanicista, el Estado, entre más pequeño fuera, más eficiente sería. Pero para ello, la privatización debe ser complementada con una política de regulación y competencia más refinada. Al no existir tal política, la privatización no ha creado un mercado menos distorsionado ni más competitivo y eficiente.

La descentralización, planteada como otro medio para modernizar el Estado, sólo se llevó a cabo en lo concerniente al sector privado, al otro participante, los gobiernos locales, en los cuales el gobierno actual pensó al comienzo, lo dejó de lado. En efecto, el presidente Calderón se proponía dos cosas: (a) "vamos a ayudar a fortalecer la capacidad de las municipalidades para que asuman las responsabilidades que emanen de la descentralización de los servicios públicos" y (b) "buscaremos mecanismos que permitan la mayor participación de las comunidades, para que se conviertan en los protagonistas principales en la solución de sus problemas y sean promotores de su propio desarrollo". Concebida de esta forma, la descentralización en beneficio de las municipalidades contenía un potencial democratizador de envergadura y, precisamente por ello, al final, el gobierno de Calderón no se atrevió a dar este paso y el poder sigue estando centralizado, En buena medida, las municipalidades siguen dependiendo económica y políticamente del gobierno central. Tampoco quiso descentralizar el sistema electoral para promover la participación ciudadana masiva. El recelo ante la descentralización ha llevado al gobierno incluso a controlar de manera particular a las organizaciones no gubernamentales en general y a las orientadas al desarrollo y a la autonomía del poder local en particular.

A favor de no descentralizar se puede argumentar la poca capacidad gestora del poder local -y por eso se habló de proporcionársela - y la escasez de fondos — que es real—, pero, sin duda, pesó más el temor a la democratización que hubiera conllevado. No todas las municipalidades están controladas por ARENA, la transferencia de competencias, capacidad y fondos po- 
tenciaría el poder local en detrimento del central, y el protagonismo de la comunidad en la solución de sus propios problemas abriría nuevos espacios y alteraría la correlación de fuerzas sociales y políticas.

En su primer discurso, el presidente Calderón se mostró preocupado por la tolerancia social, a la cual llamó "respeto humano". que, en realidad significa respeto a las conveniencias sociales, cuando lo que quería decir, a juzgar por el contenido del texto, era otra cosa distinta: "debemos defender el pluralismo ideológico frente a la confrontación sistemática, la imposición autoritaria, la prepotencia y la violencia política". La confusión del respeto humano con la tolerancia se encuentra en la ideología de ARENA. De todas maneras, sabiendo que el país salía de una guerra larga y cruel, el presidente Calderón interpretó bien el sentimiento predominante al declarar "no queremos más confrontación, ni mucho menos polarización" y, por lo tanto, prometió trabajar "por la colaboración entre todas las fuerzas políticas y sociales, para llevar adelante el gran proyecto nacional".

Aunque la polarización persiste, es aquí donde se encuentran algunos logros importantes del gobierno de Calderón. No cabe duda que su gobierno ha sido bastante tolerante de cara a la oposición política y las fuerzas sociales. En la actualidad, existe espacio suficiente para la libertad de expresión. Las limitaciones provienen de la autocensura de los medios de comunicación social, los cuales calculan hasta dónde les está permitido llegar, y de las presiones a las que son sometidos por el poder político y económico. Con todo, en algunos momentos críticos, el presidente Calderón promovió "el diálogo, la comunicación franca y el cumplimiento de los compromisos" con los representantes de los partidos políticos y de algunas fuerzas sociales.

El presidente Calderón hizo mucho énfasis en combatir la corrupción - "nuestra gestión no tolerará corrupción de ninguna índole" - y en gobernar de manera honesta - "nos comprometemos a una gestión pulcra y respetuosa de los asuntos públicos". Cinco años después, el gobierno salvadoreño no es menos corrupto que muchos otros gobiernos latinoamericanos.

En este contexto de apertura y diálogo, el presidente Calderón integró un consejo y dos comisiones nacionales pluralistas para asesorar al gobierno en la esfera de la seguridad pública, diagnosticar el estado de la educación y proponer líneas de acción y para establecer los principios de un plan de nación. Es así como el Ministro de Seguridad está asesorado por un Consejo Nacional de Seguridad Pública y la Comisión de Educación, Ciencia y Desa- 
rrollo presentó su Propuesta: transformar la educación para la paz y el desarroUlo en El Salvador y Consenso y política pública en la educación salvadoreña; mientras que la Comisión Nacional de Desarrollo elaboró las Bases para el plan de nación y los Temas claves para el plan de nación. Consulta especializa$d a$. Estos trabajos son un referente obligado tanto para educación como para la planificación del país.

Hubo dos intentos fallidos para introducir reformas en dos áreas cruciales, la electoral y la salud. Al calor de los resultados de la primera vuelta electoral de 1994, Calderón se comprometió a integrar una comisión para revisar y actualizar la legislación electoral si llegaba a la presidencia de la república. El presidente cumplió su promesa y la comisión presentó una serie de recomendaciones, pero ARENA no se atrevió a democratizar la legislación electoral. De forma similar, el presidente Calderón designó otra comisión para lidiar con la problemática de la salud pública, pero las diferencias insuperables entre el ministerio y los gremios médicos dieron al traste con el proyecto.

Aparte de sus aportes concretos, las tres primeras comisiones muestran que es posible hacer a un lado posiciones partidistas y superar diferencias ideológicas en beneficio del interés común. Aunque el Consejo Nacional de Seguridad Pública no ha dado de sí todo lo que pudiera haber dado por las fuertes reservas del ministro del ramo. Cabe destacar, sin embargo, que las comisiones dedicadas a educación y a repensar la nación han contado con el reconocimiento de la opinión pública y lo que es más importante, sus trabajos han desatado dinámicas con un potencial transformador.

Más difícil ha sido trabajar "con las diferentes organizaciones de la sociedad civil, a fin de lograr alianzas en torno a nuestro plan de gobierno y encontrar soluciones" por la desconfianza que ARENA profesa hacia quienes no militan en sus filas, $y$ porque no ha habido plan alguno alrededor del cual construir tales alianzas. La Comisión Nacional de Desarrollo fue integrada casi al final del mandato presidencial, por lo tanto, sus aportes deberán ser retomados por el nuevo gobierno. De todas maneras, su tarea es, en sí misma, muy importante, ya que ha recogido el parecer de amplios sectores de la población, tanto dentro como fuera del país.

Mucho más difícil han sido las relaciones del poder ejecutivo con la asamblea legislativa. El presidente Calderón estableció su posición con claridad en su primer discurso: "deseamos manifestarle a la oposición que vamos a mantener una comunicación abierta con la asamblea, para recibir sus opciones y encontrar los consensos básicos". En la práctica, ha predominado lo que el presidente dijo querer evitar, la imposición de la mayoría simple de ARENA o de la mayoría cualificada de éste y sus incondicionales. La comunicación con la oposición política no ha sido fluida ni constante. El poder ejecutivo no se ha mostrado interesado por conocer las opiniones de la oposición. Si algo ha caracterizado la discusión legislativa ha sido la confronta- 
ción sistemática, la prepotencia $y$ la violencia verbal, a la cual todos los diputados han contribuido.

La experiencia de diálogo $y$ negociación adquirida durante el largo proceso que llevó a los

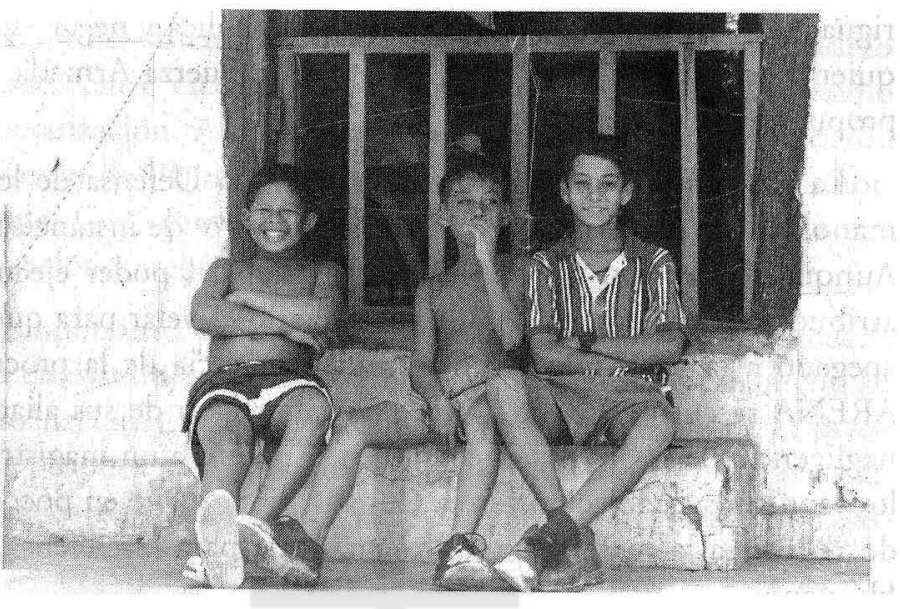
acuerdos de paz no pudo ser retomada por los partidos políticos, predominando la polarización. Si bien a ella han contribuido dos de los protagonistas más importantes de los acuerdos de paz, ARENA tiene más responsabilidad por controlar el poder ejecutivo y tener mayoría en la asamblea legislativa. En lugar de promover la discusión abierta de los problemas nacionales, ha recurrido a la polarización como medio para consolidar su poder; en lugar de "gobernar interpretando las aspiraciones del pueblo", tal como el presidente Calderón pretendía, ha recurrido a la imposición caprichosa, aun en contra de los intereses de las mayorías populares. Ha habido apertura, pero no tanta como para "fomentar el amplio desenvolvimiento de todas las corrientes de pensamiento", ni para madurar las ideas, "limitando [así] las posibilidades de encontrar mejores opciones".

Un avance decidido en estas áreas así como también en la satisfacción de las necesidades de la mayoría de la población hubiera redundado en el fortalecimiento de la institucionalidad del Estado, un complemento importante para la estabilidad macroeconómica y un requisito indispensable de la democratización. El Estado salvadoreño sigue mostrando un déficit importante en institucionalidad. La gestión estatal se caracteriza aún por la discrecionalidad y por la falta de contrapesos y controles reales. No se evalúan los resultados ni se deducen responsabilidades. El poder ejecurivo y, en concreto, la presidencia de la república tienen un peso específico demasiado grande, el cual no es contrarrestado por una independencia real de los otros dos poderes ni por instancias eficaces de control y supervisión.

Los funcionarios públicos no se consideran obligados a dar cuenta de su gestión, ni siquiera cuando han sido electos por el voto ciudadano. El presidente Calderón pudiendo sentar un precedente al respecto, más bien ha hecho lo contrario al ejercer el poder de una manera caprichosa. Es así como se permitió recibir en su despacho a un conocido dirigente de ARENA buscado por la justicia, acusado de fraude financiero, intervenir en algunas ave- 
riguaciones de la Fiscalía General de la República y negar ascensos militares a quien tiene derecho a ellos, sólo porque la Fuerza Armada no incluyó en la propuesta a sus amigos.

La elección del nuevo Procurador para la Defensa de los Derechos $\mathrm{Hu}$ manos ilustra la resistencia al control por parte de instancias independientes. Aunque la elección misma no es potestad del poder ejecutivo, una de las atribuciones principales de este funcionario es velar para que el Estado actúe apegado a la ley. Molesto por la independencia de la procuradora anterior, ARENA se curó en salud y con la colaboración de sus aliados y gracias a la negligencia de la oposición colocó en el puesto a un magistrado que no llena los requisitos establecidos en la Constitución, y que en pocos meses ha logrado reducir a la inanidad a la Procuraduría para la Defensa de los Derechos Humanos.

\section{Lecciones para los próximos cinco años}

El gobierno de Calderón ha hecho bien algunas cosas y ello es bueno para el país en general y para la mayoría de la población en particular; pero ha hecho bien otras cosas, que no son buenas para todos y en concreto para los salvadoreños desempleados y pobres. ${ }^{7}$ Es así como la estabilidad macroeconómica, aunque en sí misma es importante, su alcance es muy pequeño. Si se quiere, evitó males mayores, pero no ha sido capaz de generar prosperidad y bienestar. En realidad, la estabilidad sólo contribuye al crecimiento económico, una meta limitada, en sí misma, aun cuando alcanza los estimados mínimos necesarios para disminuir el nivel de pobreza. Al no complementar la política de estabilización con una vigorosa política social y otra de institucionalización del Estado, el gobierno de Calderón no ha podido atender el "problema de la pobreza integralmente, impulsando programas de promoción humana y facilitando a las personas más desposeídas su incorporación al trabajo productivo, para fomentar el auténtico bienestar" ni tampoco ha podido obtener resultados relevantes en el no menos grave de la violencia y la inseguridad.

Desde esta perspectiva integral, el avance más notable ha tenido lugar en educación, una inversión importante, cuyos resultados son de mediano y largo plazo; pero si ésta no es acompañada por otras políticas sectoriales y por programas específicos, orientados de manera directa a erradicar la pobreza y el desempleo en los sectores más afectados, El Salvador avanzará poco y penosamente hacia su transformación.

Al gobierno de Calderón le faltó una visión integral de la realidad nacional, que le permitiera formular políticas coherentes y eficaces, y un plan mínimo de trabajo, que orientara las acciones y conforme al cual evaluar los resultados. No se ha tratado de mala voluntad, sino de una concepción insuficiente de la gestión pública y las necesidades nacionales, agravada por 
las limitaciones reales del sistema capitalista. Todavía no se ha comprendido la relación intrínseca entre crecimiento, desigualdad, protección del medio ambiente y democratización. Al inicio de su gestión, el presidente Calderón suprimió el Ministerio de Planificación como quien se liberaba de un enorme peso socializante. Casi cinco años después, comprendiendo quizás la utilidad de la planificación, integró la Comisión Nacional de Desarrollo.

Otra carencia importante, también debida a una concepción inadecuada de la realidad, ha consistido en no relacionar las promesas gubernamentales con el presupuesto nacional. Hay que reconocer que las metas que el presidente Calderón se propuso al asumir su cargo respondían bastante bien a las necesidades de la mayoría de la población salvadoreña, pero no estaban articuladas ni priorizadas y sobre todo exigían elevar el gasto social más allá de los límites presupuestarios y "un cambio de actitud, un cambio de mentalidad, un cambio de enfoque" para lo cual ni ARENA ni el mismo presidente estaban preparados. El desafío ya no radica en diagnosticar las necesidades del pueblo salvadoreńo, sino en encontrar la manera eficiente para satisfacerlas en breve.

Los candidatos a la presidencia de la república debieran analizar con detenimiento los aciertos y desaciertos del gobierno de Calderón y el por qué de cada uno de ellos. Este ejercicio de análisis pondría realismo en el discurso de los candidatos. No parten de cero. El presidente Calderón hizo promesas similares hace cinco años y sólo pudo cumplir una pequeña parte. No está de más reflexionar sobre las razones que explican este desempeño tan modesto. La deficiencia no proviene del planteamiento de los problemas, sino de la solución. A juzgar por los resultados, la solución dada es mala y una mala solución suele arrojar malos resultados. Por esto, tal como sentenciaba Ignacio Ellacuría, es peor tener una mala solución que no tenerla. Si el nuevo gobierno continúa dando malas soluciones, dentro de cinco años, el nuevo presidente se encontrará con que también habrá cosechado algunos logros, pero El Salvador continuará siendo el mismo país de siempre.

San Salvador, 11 de febrero de 1999. 